\title{
Assessment of visual perception in adolescents with a history of central coordination disorder in early life - 15-year follow-up study
}

Wojciech Kiebzak², Ireneusz M. Kowalski², Małgorzata Domagalska³, Andrzej Szopa³, Michał Dwornik4, Jolanta Kujawa ${ }^{5}$, Agnieszka Stępieńn ${ }^{6}$ Zbigniew Śliwiński ${ }^{1}$

${ }^{1}$ Faculty of Health Sciences, Jan Kochanowski University, Kielce, Poland 2Faculty of Medicine, University of Warmia and Mazury, Olsztyn, Poland 3Kinesiology Division, Department of Physiotherapy, Silesian Medical University, Katowice, Poland

${ }^{4}$ Division of Rehabilitation, Department of Physiotherapy, 2nd Medical Faculty, Medical University of Warsaw, Poland

5Department of Medical Rehabilitation, Medical University of Lodz, Poland 'Department of Rehabilitation, Faculty of Rehabilitation, University of Physical Education, Warsaw, Poland

Submitted: 5 January 2011

Accepted: 31 July 2011

Arch Med Sci 2012; 8, 5: 879-885

DOI: 10.5114 /aoms.2012.28638

Copyright (c) 2012 Termedia \& Banach

\section{Abstract}

Introduction: Central nervous system damage in early life results in both quantitative and qualitative abnormalities of psychomotor development. Late sequelae of these disturbances may include visual perception disorders which not only affect the ability to read and write but also generally influence the child's intellectual development. This study sought to determine whether a central coordination disorder (CCD) in early life treated according to Vojta's method with elements of the sensory integration (S-I) and neuro-developmental treatment (NDT)/Bobath approaches affects development of visual perception later in life. Material and methods: The study involved 44 participants aged 15-16 years, including 19 diagnosed with moderate or severe CCD in the neonatal period, i.e. during the first 2-3 months of life, with diagnosed mild degree neonatal encephalopathy due to perinatal anoxia, and 25 healthy people without a history of developmental psychomotor disturbances in the neonatal period. The study tool was a visual perception IQ test comprising 96 graphic tasks.

Results: The study revealed equal proportions of participants $(p<0.05)$ defined as very skilled (94-96), skilled (91-94), aerage (71-91), poor (67-71), and very poor (0-67) in both groups. These results mean that adolescents with a history of CCD in the neonatal period did not differ with regard to the level of visual perception from their peers who had not demonstrated psychomotor development disorders in the neonatal period.

Conclusions: Early treatment of children with CCD affords a possibility of normalising their psychomotor development early enough to prevent consequences in the form of cognitive impairments in later life.

Key words: sensory integration disorder, early therapy according to Vojta, visual perception disorder.

\section{Introduction}

The normal psychomotor development of a child is determined by a genetic programme that is, however, considerably modified by environmental

\section{Corresponding author:}

Wojciech Kiebzak PhD, PT

University of Jan Kochanowski

5 Żeromskiego St

25-369 Kielce, Poland

Phone/fax: +48 413615525

E-mail: kiebzakw@wp.pl 
influences [1-10]. The details of implementation of this programme are therefore liable to individual variation, for example with regard to the timeline of reaching consecutive developmental milestones or the individual sequences of motor skills acquisition. This individual ontogenetic path of development is closely related to the psychosomatic integrity of man. The development is most commonly described as a process of sensory integration and is reflected, among others, in the organisation of sensory inputs [11-17].

An especially convincing explanatory framework in this field is the theory of Jean Ayres, who presented a model of development of sensory integration (S-I). The process consists of four levels, with correlations including a marked association between the development of muscle tone and eyeball movement and coordination (S-I Level 1) and the sense of selfesteem, self-trust, and logical and abstract thinking (S-I Level 4) $[1,7,8]$.

Nervous system damage results in both quantitative and qualitative deviations from normal psychomotor development [18]. This is when disturbances of integration processes become evident, initially as motor disturbances [19-25] but later also as disturbances in perception processes and behaviour [26-34]. Late sequelae of these disturbances may include visual perception disorders which not only affect the ability to read and write but also generally influence the child's intellectual development [35-38]. These disorders may adversely affect the process of concrete thinking and the development of directional and spatial orientation, causing specific difficulties in learning geography, geometry and foreign languages.

The most important disturbances of psychomotor development that adversely affect learning to read and write are disturbances of the development of postural reflexes in the neonatal period in the form of prolonged dominance of primitive reflexes with an accompanying delay or disturbance in the development of normal postural responses [39-47]. It is also now assumed that disturbances in the development of postural reflexes may impair higher cortical functions, in particular those related to education. However, they are viewed as signs of developmental coordination disorder (DCD) [48-50]. The DCD is commonly regarded as a developmental abnormality and has been classified under DSM-IVP (APA 1994) [51]. Children with DCD demonstrate a diverse range of dysfunctions that can be classified into three areas of psychomotor development: gross motor skills, fine motor skills and pro-social behaviour. Gross motor skill disorder, presenting mainly as abnormalities of muscle tone and the development of postural responses, can be diagnosed in the early period of motor development. Such children show signs of central coordination disorder (CCD) already in the first months of life, which according to the diagnostic approach of Vojta indicates disturbed development of postural responses [20, 21]. Some of those children go on to develop signs of infantile cerebral palsy (ICP) later in life, and some exhibit an apparent regression of these symptoms that will manifest again in later life, most frequently as impaired manual skills and disturbances of the development of manual and graphic functions, as well as disturbances of the development of visuomotor coordination and, consequently, visual analysis and synthesis [52]. Together, these abnormalities may contribute to dyslexia and disorders of lateralisation and visual perception and underlie learning difficulties and psychosocial problems [53-56]. This paper seeks to provide answers to the following questions:

1. Does therapy of central coordination disorder in early life according to Vojta with elements of the SI and NDT/Bobath methods influence the level of development of visual perception later in life? 2. Do the results of assessment of visual perception in adolescents with a history of early central coordination disorder treated according to Vojta with elements of the SI and NDT/Bobath method differ from those of their peers without developmental abnormalities in the neonatal period?

\section{Material and methods}

The study involved 44 participants aged 15 and 16 years, including 19 (9 girls and 10 boys) diagnosed with moderate or severe CCD in the neonatal period, i.e. during the first 2-3 months of life, with diagnosed mild degree neonatal encephalopathy due to perinatal anoxia $[57,58]$ and 25 healthy people (12 girls and 13 boys) without a history of developmental psychomotor disturbances in the neonatal period. The first group was an experimental group (group A), and the second group (group B) was a control group. All members of the experimental group had received a diagnosis of CCD and subsequently undergone therapy according to Vojta with elements of the S-I and NDT methods until their psychomotor development returned to normal (after a mean of 10 months of therapy). In the period from the end of therapy to the time of the IQ test no therapy was applied. The assessment tool was a visual perception IQ test based on Raven's Matrices, and that comprised 96 graphic tasks to be completed in 50 min [59]. Each task was based on logically matching one of 5 suggested items as the missing element of a picture.

\section{Statistical analysis}

Statistical analysis to assess the results of the IQ test involved the $\chi^{2}$ test, Pearson's C, Student's $t$ test, calculation of the discriminating power of 
Table I. Best-fit curve data for the experimental group (A)

\begin{tabular}{|c|c|c|c|c|c|c|c|c|}
\hline \multirow[t]{2}{*}{ Class } & \multirow{2}{*}{$\begin{array}{c}\text { Class } \\
\text { interval }\end{array}$} & \multirow{2}{*}{$\begin{array}{c}\text { Centre } \\
\text { of class } \\
\text { interval } \\
x_{k o}\end{array}$} & \multirow{2}{*}{$\begin{array}{c}\text { Deviation } \\
\text { from } \\
\text { the centre } \\
x_{k}=x_{k o}-x_{s r}\end{array}$} & \multirow{2}{*}{$\begin{array}{c}\text { Standardised } \\
\text { result } \\
z=x_{k} / s\end{array}$} & \multirow[t]{2}{*}{$Y$ value } & \multicolumn{3}{|c|}{ Number } \\
\hline & & & & & & $\begin{array}{c}\text { Expected } \\
f_{S}\end{array}$ & $\begin{array}{c}\text { Obtained } \\
f_{0}\end{array}$ & Decision \\
\hline 1 & {$[36-41]$} & 38.5 & -40.61 & -2.69 & 0.0107 & 0.08 & 1 & \\
\hline 2 & {$[42-47]$} & 44.5 & -34.61 & -2.30 & 0.0283 & 0.21 & - & \\
\hline 3 & {$[48-53]$} & 50.5 & -28.61 & -1.90 & 0.0656 & 0.50 & 1 & \\
\hline 4 & {$[54-59]$} & 56.5 & -22.61 & -1.50 & 0.1295 & 0.98 & - & \\
\hline 5 & {$[60-65]$} & 62.5 & -16.61 & -1.10 & 0.2178 & 1.65 & 1 & $\chi^{2}=26.014>21.666_{0.01 ; 9}$ \\
\hline 6 & {$[66-71]$} & 68.5 & -10.61 & -0.70 & 0.3122 & 2.36 & 2 & $H_{0}$ rejected \\
\hline 7 & {$[72-77]$} & 74.5 & -4.61 & -0.31 & 0.3802 & 2.88 & 1 & \\
\hline 8 & [78-83] & 80.5 & 1.39 & 0.09 & 0.3973 & 3.01 & 3 & \\
\hline 9 & [84-89] & 86.5 & 7.39 & 0.49 & 0.3538 & 2.68 & 3 & \\
\hline 10 & [90-95] & 92.5 & 13.39 & 0.89 & 0.2684 & 2.03 & 7 & \\
\hline
\end{tabular}

Table II. Best-fit curve data for the control group (B)

\begin{tabular}{|c|c|c|c|c|c|c|c|c|}
\hline \multirow[t]{2}{*}{ Class } & \multirow{2}{*}{$\begin{array}{c}\text { Class } \\
\text { interval }\end{array}$} & \multirow{2}{*}{$\begin{array}{c}\text { Centre } \\
\text { of class } \\
\text { interval } \\
x_{k 0}\end{array}$} & \multirow{2}{*}{$\begin{array}{l}\text { Deviation } \\
\text { from } \\
\text { the centre } \\
x_{k}=x_{k o}-x_{5 r}\end{array}$} & \multirow{2}{*}{$\begin{array}{c}\text { Standardised } \\
\text { result } \\
z=x_{k} / s\end{array}$} & \multirow[t]{2}{*}{$Y$ value } & \multicolumn{3}{|c|}{ Number } \\
\hline & & & & & & $\begin{array}{c}\text { Expected } \\
f_{S}\end{array}$ & $\begin{array}{c}\text { Obtained } \\
f_{0}\end{array}$ & Decision \\
\hline 1 & {$[36-41]$} & 38.5 & -39.38 & -2.70 & 0.0104 & 0.11 & 1 & \\
\hline 2 & {$[42-47]$} & 44.5 & -33.38 & -2.29 & 0.0290 & 0.30 & 1 & \\
\hline 3 & {$[48-53]$} & 50.5 & -27.38 & -1.88 & 0.0681 & 0.70 & 0 & \\
\hline 4 & [54-59] & 56.5 & -21.38 & -1.47 & 0.1354 & 1.39 & 0 & \\
\hline 5 & {$[60-65]$} & 62.5 & -15.38 & -1.06 & 0.2274 & 2.34 & 3 & $\chi^{2}=16.205>15.987_{0.10 ; 10}$ \\
\hline 6 & {$[66-71]$} & 68.5 & -9.38 & -0.64 & 0.3250 & 3.35 & 1 & $H_{0}$ rejected \\
\hline 7 & {$[72-77]$} & 74.5 & -3.38 & -0.23 & 0.3885 & 4.00 & 3 & \\
\hline 8 & [78-83] & 80.5 & 2.62 & 0.18 & 0.3925 & 4.04 & 5 & \\
\hline 9 & [84-89] & 86.5 & 8.62 & 0.59 & 0.3352 & 3.45 & 6 & \\
\hline 10 & [90-95] & 92.5 & 14.62 & 1.00 & 0.2419 & 2.49 & 4 & \\
\hline 11 & [96-101] & 98.5 & 20.62 & 1.42 & 0.1455 & 1.50 & 1 & \\
\hline
\end{tabular}

the task $\left(r_{d}\right)$, task difficulty coefficient $(T)$, and a structural index.

\section{Results}

Assessment of the responses to the IQ test began by determining the natural distribution of the responses by analysing the best-fit curve. The fit of the empirical data with the normal distribution was verified with the chi-squared test. The best-fit curve results are given in Tables I and II. The bestfit curves are presented in Figure 1.

The figure indicates that the IQ test turned out to be relatively easy for all participants as the curve peaks are shifted to the right relative to the axis of

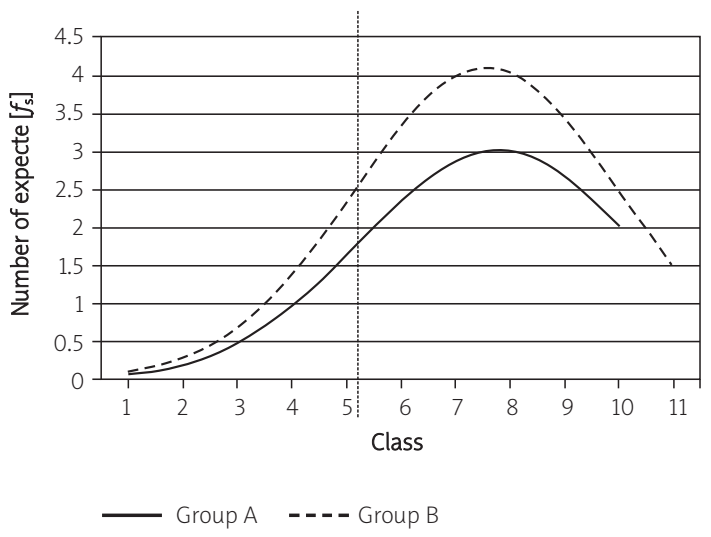

Figure 1. Best-fit curves 
Table III. Discriminating power of tasks

\begin{tabular}{|lccc|}
\hline Index & \multicolumn{2}{l}{ Number of test tasks } & Structure index \\
\cline { 2 - 3 } & $\mathrm{A}$ & $\mathrm{B}$ & \\
\hline$r_{d} \geq 0.2$ & 59 & 46 & $\begin{array}{c}1.88>1.645_{0,10} H_{0} \\
\text { rejected }\end{array}$ \\
\hline$N$ & 96 & 96 & reser \\
\hline
\end{tabular}

symmetry of the distribution and are different from one another. The null hypothesis $\left(H_{0}\right)$ was rejected for both populations since the curves did not meet the criteria for a normal distribution (for the experimental group: $\chi^{2}=26.014>\chi^{2} 0.01 ; 9=21.665$; for the control group: $\chi^{2}=16.205>\chi^{2} 0.10 ; 10=15.987$ ). A comparison of the above correlations shows that only $1 \%$ of the experimental group did not differ from the normal distribution, compared to $10 \%$ of the control group. On this basis, it was assumed that the results of the $\mathrm{IQ}$ perception skills test concerned only the two study populations and could not be generalised.

An analysis of the statistical significance of the mean differences in results between the experimental and control groups using Student's $t$ test $(t=0.266$ $>t_{0.80 ; 42}=0.255$ ) led to the rejection of the null hypothesis at $80 \%$ confidence, which meant that $80 \%$ of the populations of both groups did not differ from one another. In order to analyse the discriminating power of the task, an index of the discriminating power $r_{d}$ was calculated. The results in Table III show that the number of test tasks meeting the normal limit $r_{d} \geq 0.2$ was considerably higher for the participants in the experimental group. These results are shown in Table III.

Table V. Determination of participant skill level

\begin{tabular}{|lll|}
\hline \multirow{2}{*}{ Skill level description } & \multicolumn{2}{c|}{ Scoring intervals } \\
\cline { 2 - 3 } & Group A & Group B \\
\hline Very skilled & $(94-96]$ & $(92-96]$ \\
\hline Skilled & $(91-94]$ & $(90-92]$ \\
\hline Average & $(71-91]$ & $(71-90]$ \\
\hline Poor & $(67-71]$ & $(66-71]$ \\
\hline Very poor & $(0-67]$ & $(0-66]$ \\
\hline
\end{tabular}

Table IV. Task difficulty

\begin{tabular}{|lcccc|}
\hline Task & $\begin{array}{c}\text { Intervals } \\
\text { of difficulty } \\
\text { index }\end{array}$ & $\begin{array}{c}\text { Number } \\
\text { of test } \\
\text { tasks }\end{array}$ & \\
\cline { 2 - 4 } & A & B & \\
\hline Very difficult & {$[0-0.2)$} & - & - & - \\
\hline Difficult & {$[0.2-0.4)$} & - & - & - \\
\hline Average & {$[0.4-0.6)$} & 6 & 8 & $\begin{array}{c}0.56<0.674_{0.50} H_{0} \\
\text { accepted }\end{array}$ \\
\hline Easy & {$[0.6-0.8)$} & 35 & 25 & $\begin{array}{c}1.56>1.282_{0.20} H_{0} \\
\text { rejected }\end{array}$ \\
\hline Very easy & {$[0.8-1.0]$} & 55 & 63 & $\begin{array}{c}1.19>1.036_{0.30} H_{0} \\
\text { rejected }\end{array}$ \\
\hline & $N$ & 96 & 96 & \\
\hline
\end{tabular}

The significance of this difference was examined with the index of structure. Hypothesis $H_{0}$ was rejected at the confidence level of $p=0.10$. There were more discriminating tasks in the experimental vs. the control group $(59>46)$, which meant that the perception test tasks differentiated the experimental group to a greater extent.

The task difficulty index $(T)$ showed with $80 \%$ confidence that there were more easy test tasks in the experimental vs. the control group $(35>25)$ (Table IV). The number of very easy test tasks was higher in the control group than in the experimental group, which was ascertained with $70 \%$ confidence $(55<63)$. The above statements clearly show that the respective test profiles of the groups primarily depended on easy and very easy tasks of the visual perception test. This was also confirmed by the best-fit curve graphs. Since the best-fit curves (Figure 1) were similar to the normal curve, a characterisation of the perceptual abilities of the participants was attempted. These results are shown in Table V.

For the analysis of significance of differences between particular perception skills in both the experimental and control groups, ranges were assumed based on the test results in the experimental group. The data are shown in Table VI.

Table VI. Significance of correlations between individual perceptual skills of the participants in both the experimental group (A) and the control group (B)

\begin{tabular}{|c|c|c|c|c|c|c|}
\hline \multirow{2}{*}{$\begin{array}{l}\text { Skill level } \\
\text { description }\end{array}$} & \multirow[t]{2}{*}{ Scoring intervals } & \multicolumn{2}{|c|}{ Number of participants } & \multirow[t]{2}{*}{$\chi^{2}$} & \multirow[t]{2}{*}{ Pearson's C } & \multirow[t]{2}{*}{$\mathrm{C}_{\text {stand }}$} \\
\hline & & $A$ & B & & & \\
\hline Very skilled & $(94-96]$ & 1 & 1 & & & \\
\hline Skilled & $(91-94]$ & 2 & 1 & & & \\
\hline Average & $(71-91]$ & 11 & 17 & $1.668<1.704_{0.79 ; 4}$ & 0.19 & 0.21 \\
\hline Poor & $(67-71]$ & 2 & 1 & & & \\
\hline \multirow[t]{2}{*}{ Very poor } & $(0-67]$ & 3 & 5 & $H_{0}$ accepted & & Convergence steady \\
\hline & $N$ & 19 & 25 & & & \\
\hline
\end{tabular}


Significance was verified with the $\chi^{2}$ test. The following figures were obtained: $\chi^{2}=1.668<\chi_{0.79 ; 4}^{2}=$ $=1.704$. Thus the null hypothesis was accepted with almost $80 \%$ confidence. The fit between results was certain, estimated on the basis of the contingency measure (Pearson's C) and a model specifying the maximum values of Pearson's $C$ for different degrees of freedom. This result was the same as that obtained in the analysis of significance of differences in means between the experimental and control group ( $t$ test statistic). The proportions of participants classified as very skilled, skilled, poor and very poor were balanced in both groups (Table VI).

\section{Discussion}

The role of visual perception in an individual's psychomotor development and the need to include this perceptual modality in the diagnostic work-up has been stressed by the authors of all currently popular diagnostic systems [60]. These authors attach considerable importance in the diagnosis of central coordination disorder, among other factors, to assessment of the distribution of muscle tone, postural responsiveness and visuomotor coordination.

The theory positing a hierarchy of levels of sensory integration assumes a correlation between logical thinking (level IV) and proper development of muscle tone, development of reflex postural activity (level I), development of visuomotor coordination (level II), and development of the ability to identify shapes in space (level III) $[1,7,8]$. It seemed very interesting to find out whether disturbed development of muscle tone and reflex postural activity in early life, typical features of CCD, would influence the development of visual perception as assessed in adolescence. It also appeared interesting to determine whether these results would differ from those achieved by adolescents of the same age without a history of developmental disorders.

Many studies have confirmed that the persistence of primitive postural reflexes beyond the sixth month of life and the absence of or delay in the development of proper postural responses are reliable indicators of neurological disorders that in turn can affect both motor and mental development. A study by Blythe (1979) of a group of 54 children with known dyslexia who underwent several standard neurological tests to assess any abnormalities of the development of postural responses showed that the persistence of primitive reflexes and absence of normal postural responses were significantly associated with signs of dyslexia in these children $[61,62]$.

A study by Wilkinson of 28 boys and 35 girls aged between 7.7 and 8.6 years from four different primary schools involved simultaneous assessment of the activity of primitive reflexes (using standard neurological tests), a wide range of motor abilities (Achievement Test) and the level of intelligence
(Non-Reading Intelligence Test). The results showed that disturbed development of postural responses contributed significantly to problems at school and inadequate school achievement [63]. In turn, a study by O'Dell and Cook unequivocally confirmed that disturbed development of postural responses is a significant factor among children with dyslexia, attention deficit disorder (ADD) and attention deficit hyperactivity disorder (ADHD) [64].

The results of the present study, however, showed that the proportions of participants classified as very skilled, skilled, poor and very poor were similar between the groups. These data mean that the level of visual perception in the adolescents with a history of CCD in the neonatal period was not different from that of their peers without a history of such disturbances.

It should doubtless be assumed that disturbances of early postural responses affect the acquisition and automatisation of more complex higherorder skills. Immature adaptive postural mechanisms not only impair postural and motor development but also disturb the child's ability to express his or her intelligence in all tasks dependent on motor skills, such as reading and writing, which in turn are essential for all education. Their early signs, examples of which undoubtedly include disturbances of the development of reflexes and postural responses, can, however, be detected early enough (early detection) to allow early appropriate rehabilitation (early intervention) so that motor development can be normalised before disorganised development of other spheres occurs [65]. It may be supposed that early institution of therapy according to Vojta (supplemented with elements of the NDT/Bobath and S-I methods), which aims primarily at normalising the development of muscle tone and postural responses, enabled the children with a history of moderate or severe CCD to achieve optimal developmental potential. The accomplishment of this goal is made possible through, most importantly, monitoring the diagnostic and therapeutic process, following established management procedures, and patient empowerment $[66,67]$.

Similar results have been published by ThiesenHutter, who demonstrated lack of differences in the domains of aggressiveness, fearfulness, shyness, neurotic tendencies, independence and maturity between 88 children rehabilitated according to Vojta and 88 matched healthy controls.

In conclusion, the integrity of results of the 15-year follow-up forms the basis for the following conclusions:

1. Early therapy according to Vojta with elements of the S-I and NDT/Bobath methods in children with central coordination disorder affords a possibility of normalising their motor development and avoiding later consequences in the form of cognitive impairments. 
2. Adolescents with a history of CCD in the neonatal period who were rehabilitated according to Vojta's method with elements of the SI and NDT methods did not differ with regard to the level of visual perception from their peers who had not demonstrated psychomotor development disorders in the neonatal period.

\section{Acknowledgments}

Thanks for Michał Kosztołowicz PhD for methodology support.

\section{References}

1. Ayres J. Sensory Integration and the Child. Los Angeles: Western Psychological Services; 1979.

2. Hadders-Algra M. The neuronal group selection theory: a framework to explain variation in normal motor development. Dev Med Child Neurol 2000; 42: 566-72.

3. Hadders-Algra M. The neuronal group selection theory: promising principles for understanding and treating developmental motor disorders. Dev Med Child Neurol 2000; 42: 707-15.

4. Johansson B. Brain plasticity and stroke rehabilitation. The Willis lecture. Stroke 2000; 31: 223-30.

5. Kossut M. Plasticity of the barrel cortex neuron. Prog Neurobiol 1992; 39: 389-422.

6. Kossut M. Effects of sensory deprivation upon a single cortical vibrissal column: a 2DG study. Exp Brain Res 1992; 90: 639-42.

7. Ayres J. Improving academic scores through sensory integration. J Learn Disabil 1972; 5: 338-343.

8. Ayres J. Sensory integration and learning disorders. Los Angeles (CA): Western Psychological Services; 1973.

9. Cramer S, Chopp M. Recovery recapitulates ontogeny. Trends Neurosci 2000; 23: 265-71.

10. de Graaf-Peters VB, Hadders-Algra M. Ontogeny of the human central nervous system: what is happening when? Early Hum Dev 2006; 82: 257-66.

11. Koch C, Segev I. The role of single neurons in information processing. Nat Neurosci 2000; 3: 1171-7.

12. Stein BE, Perrault TJ Jr, Stanford TR, Rowland BA. Postnatal experiences influence how the brain integrates information from different senses. Front Integr Neurosci 2009; 3: 21.

13. Miller LJ, Nielsen DM, Schoen SA, Brett-Green BA. Perspectives on sensory processing disorder: a call for translational research. Front Integr Neurosci 2009; 3: 22.

14. Kratz SV. Sensory integration intervention: historical concepts, treatment strategies and clinical experiences in three patients with succinic semialdehyde dehydrogenase (SSADH) deficiency. J Inherit Metabol Dis 2009; 32: 353-60.

15. Fan J, Gu X, Guise KG, et al. Testing the behavioral interaction and integration of attentional networks. Brain Cogn 2009; 70: 209-20.

16. Bundy AC, Lane SJ, Fisher AG, Murray EA. Sensory Integration: theory and Practice. $2^{\text {nd }}$ ed. 2002. Philadelphia: F.A. Davis; 2002;

17. Schaaf RC, Miller LI. Occupational therapy using a sensory integrative approach for children with developmental disabilities. Ment Retard Dev Disabil Res Rev 2005; 11: 143-8.

18. Zygmunt A, Stanczyk J. Methods of evaluation of autonomic nervous system function. Arch Med Sci 2010; 6: 11-8.

19. Bobath K. The normal postural reflex mechanism and its deviation in children with cerebral palsy. Physiotherapy 1971; 57: 515-25.
20. Vojta V. Early diagnosis and therapy of cerebral movement disorders in childhood. C. Reflexogenous locomotion - reflex creeping and reflex turning. C2. Its use in 207 risk children. Analysis of the final results. Z Orthop Ihre Grenzgeb 1973; 111: 292-309.

21. Vojta V. Early management of children with cerebral palsy hazards. Analysis of final results. Monatsschr Kinderheilkd 1973; 121: 271-3.

22. Sadowska L, Gomulska K, Krefft A, Gomulska K, MysłekPrucnal M. Early synthetic diagnostics of cerebral palsy in children at risk treated with neurodevelopmental method. Fizjoter Pol 2006; 5: 134-42.

23. Köng E. Early detection of cerebral motor disorders. In: Fossberg $\mathrm{H}$, Hirschberg $\mathrm{H}$, editors. Movement disorders in children. Basel: Med Sport Science Karger; 1992. p. 80-5.

24. Sadowska L. Vaclav Vojta's neurokinesiological concept for the diagnosis and therapy of children with disturbances of motor development. Ortop Traumatol Rehabil 2001; 3: 519-26.

25. Banaszek G. Vojta's method as the early neurodevelopmental diagnosis and therapy concept. Przegl Lek 2010; 67; 67-76.

26. Prechtl HFR. Qualitative changes of spontaneous movements in fetus and preterm infant are a marker of neurological dysfunction. Early Hum Dev 1990; 23: 151-8.

27. Prechtl HFR, Bos AF, Cioni G, et al. Spontaneous motor activity as a diagnostic tool. Demonstration video. London: The GM Trust; 1997.

28. Hopkins B, Prechtl HFR. A qualitative approach to me development of movement during early infancy. In: Prechtl HFR editior. Continuity of neural function from prenatal to postnatal life. Oxford: Blackwell; Clin Dev Med; 1984.

29. Prechtl HF, Einspieler C, Cioni G, Bos AF, Ferrari F, Sontheimer D. An early marker for neurological deficits after perinatal brain lesions. Lancet 1997; 349: 1361-3.

30. Ferrari F, Prechtl HF, Cioni G, et al. Posture, spontaneous movements, and behavioural state organisation in infants affected by brain malformations. Early Hum Dev 1997; 50: 87-113.

31. Imamura S, Sakuma K, Takahashi T. Follow-up study of children with cerebral coordination disturbance (CCD, Vojta). Brain Develop 1983; 5: 311-4.

32. Schmuckler MA, Jewell DT. Infants' visual-proprioceptive intermodal perception with imperfect contingency information. Dev Psychobiol 2007; 49: 387-98.

33. Nemeth D, Hallgató E, Janacsek K, Sándor T, Londe Z. Perceptual and motor factors of implicit skill learning. Neuroreport 2009; 20: 1654-8.

34. Chary C, Méary D, Orliaguet JP, David D, Moreaud O, Kandel S. Influence of motor disorders on the visual perception of human movements in a case of peripheral dysgraphia. Neurocase 2004; 10: 223-32.

35. Coleman R, Piek JP, Livesey DJ. A longitudinal study of motor ability and kinaesthetic acuity in young children at risk of developmental coordination disorder. Hum Mov Sci 2001; 20: 95-110.

36. American Psychiatric Association. Diagnostic and statistical manual of mental disorder: DSM-IV. $4^{\text {th }}$ ed. Washington, DC: American Psychiatric Association; 1994.

37. Hadders-Algra M. Early brain damage and the development of motor behavior in children: clues for therapeutic intervention? Neural Plasticity 2001; 8: 31-49.

38. Sugihara T, Diltz MD, Averbeck BB, Romanski LM. Integration of auditory and visual communication information in the primate ventrolateral prefrontal cortex. J Neurosci 2006; 26: 11138-47.

39. Bobath K, Bobath B. Abnormal postural reflex activity caused by brain lesions. London: William Heineman; 1965. 
40. Dewey D, Wilson BN. Developmental coordination disorder: what is it? Phys Occup Ther Pediatr 2001; 20: 5-27.

41. Wright HC, Sugden DA. A two-step procedure for the identification of children with developmental co-ordination disorder in Singapore. Dev Med Child Neurol 1996; 38 : 1099-105.

42. Crawford SG, Wilson BN, Dewey D. Identifying develop mental coordination disorder: consistency between tests. Phys Occup Ther Pediatr 2001; 20: 29-50.

43. Bender ML. The Bender-Purdue reflex test. San Rafael (CA): Academic Therapy Publications; 1976.

44. Fiorentino MR. Reflex Testing methods for evaluating central nervous system development. $2^{\text {nd }}$ ed. Springfield, III: Charles C Thomas, Publisher; 1981.

45. Levitt S. Treatment of cerebral palsy and motor delay. $4^{\text {th }}$ ed. Oxford: Blackwell Scientific Publications; 1984.

46. Rosen GD, Sherman GF, Galaburda AM. Dyslexia and brain pathology: experimental animal models. In: Galaburda AM, editor. Dyslexia and development: neurobiological aspects of extra-ordinary brains. Cambridge, MA: Harvard University Press; 1993. p. 89-111.

47. Whitmore K, Bax M. What do we mean by SLD? A historical perspective. In: Whitmore K, Hart H, Willems G. editors. A neurodevelopmental approach to specific learning disorders. Suffolk: Mackeith Press; 1999. p. 1-23.

48. Dyck M, Piek J. How to distinguish normal from disordered children with poor language or motor skills. Int J Lang Commun Disord 2010; 45: 336-44.

49. Hadders-Algra M. Developmental coordination disorder: is clumsy motor behavior caused by a lesion of the brain at early age? Neural Plast 2003; 10: 39-50.

50. Zwicker JG, Missiuna C, Boyd LA. Neural correlates of developmental coordination disorder: a review of hypotheses. J Child Neurol 2009; 24: 1273-81.

51. Sigmundsson H, Haga M. Research on children with development coordination disorder - some challenges! Percept Mot Skills 2010; 110: 114-6.

52. Esch T, Stefano GB. Endogenous reward mechanisms and their importance in stress reduction, exercise and the brain. Arch Med Sci 2010; 6: 447-55.

53. Punt M, DE Jong M, DE Groot E, Hadders-Algra M. Minor neurological dysfunction in children with dyslexia. Dev Med Child Neurol 2010; 52: 1127-32.

54. McPhilips M, Sheehy N. Prevalence of persistent primary reflexes and motor problems in children with reading difficulties. Dyslexia 2004; 10: 316-38.

55. Hairston WD, Burdette JH, Flowers DL, Wood FB, Wallace MT. Altered temporal profile of visual-auditory multisensory interactions in dyslexia. Exp Brain Res 2005; 166: 474-80.

56. Blau V, van Atteveldt N, Ekkebus M, Goebel R, Blomert L. Reduced neural integration of letters and speech sounds links phonological and reading deficits in adult dyslexia. Curr Biol 2009; 19: 503-8.

57. Sarnat HB, Sarnat MS. Neonatal encephalopathy following fetal distress. A clinical and electroencephalographic study. Arch Neurol 1976; 33: 696-705.

58. Badawi N, Kurinczuk JJ, Keogh JM, et al. Intrapartum risk factors for newborn encephalopathy: the Western Australian case-control study. BMJ 1998; 317: 1554-8.

59. Raven J, Raven JC, Court JH. Manual for Raven's progressive matrices and vocabulary scales. Section 3: The standard progressive matrices. San Antonio, TX: Harcourt Assessment; 2004

60. Putzar L, Goerendt I, Lange K, Rösler F, Röder B. Early visual deprivation impairs multisensory interactions in humans. Nat Neurosci 2010; 10: 1243-5.
61. Blythe P, McGlown DJ. An organic basis for neuroses and educational difficulties. Chester: Insight Publications; 1979.

62. Blythe SG. Neurological dysfunction as a significant factor in children diagnosed with dyslexia. In: Presentations from the $5^{\text {th }}$ British Dyslexia Association International Conference; 2001. 04.18-21; University of York, UK.

63. Wilkinson $\mathrm{G}$. The relationship of primitive postural reflexes to learning difficulty and underachievement. Unpublished M. Ed thesis. Newcastle: University of Newcastle-uponTyne; 1994.

64. O'Dell NE, Cook PA. Stopping Hyperactivity - a new solution. New York: Avery Publishing Group; 1997.

65. Kiebzak W, Szmigiel Cz. Monitoring the process of rehabilitation in children with disorders of central coordination. Fizjoter Pol 2003; 3: 243-9.

66. Kiebzak W, Starczyńska M, Śliwiński Z, et al. The importance of quality in the practice of physiotherapy. The case of the Regional Specialised Paediatric Hospital in Kielce, Fizjoter Pol 2007; 2: 133-44.

67. Kiebzak W, Kowalski IM, Kiebzak M. Model of therapeutic rehabilitation. Rehabil Med 2008; 2: 31-3. 